\title{
Effect of earthworm inoculation on the bioremediation of used engine oil contaminated soil
}

\author{
Alewo Opuada AMEH $^{1 *}$, Ibrahim Ali MOHAMMED-DABO ${ }^{2}$, Sani IBRAHIM ${ }^{3}$, \\ Joseph Baba $\mathrm{AMEH}^{4}$, Yahuza TANIMU ${ }^{5}$ and Tajudeen Kolawole BELLO ${ }^{6}$ \\ ${ }^{1,2,6}$ Department of Chemical Engineering, A.B.U., Zaria. 810261. \\ ${ }^{3}$ Department of Biochemistry, Ahmadu Bello University, Zaria. \\ ${ }^{4}$ Department of Microbiology, Ahmadu Bello University, Zaria. \\ ${ }^{5}$ Department of Biological Sciences, Ahmadu Bello University, Zaria. \\ * Corresponding author, E-mail: alewooameh@yahoo.com; +2348035600744
}

\begin{abstract}
The effect of earthworm (Eudrilus eugeniae) on the bioremediation of used engine oil contaminated soil, amended with poultry manure, was investigated. Investigation into the effect of initial concentration of used engine oil, in soil, for earthworm inoculated samples showed that the biodegradation rate of used engine oil contaminant increased with increasing initial concentration of used engine oil. For initial used engine oil concentration of $5,10,15$ and $20 \mathrm{~g} / \mathrm{kg}$ soil, the drop in total petroleum hydrocarbon was found to be -16.91 , $20.82,34.68$ and $36.28 \%$ respectively after 42 days of treatment. Investigation into the effect of earthworm concentration showed that the use of earthworms did not result in catalysis of the bioremediation process as the extent of biodegradation for the sample without earthworm was found to be higher than those of all concentrations of earthworm considered ( $5-20$ worms $/ \mathrm{kg}$ soil). However, the rate of bioremediation was found to increase with increase in earthworm concentration (as earthworm concentration was increased from 5 to 20 worms per $\mathrm{kg}$ of used engine oil contaminated soil). Similarly when the rate of bioremediation in the without-earthworm but manually tilled and the without-earthworm and untilled samples where compared with samples inoculated with earthworm for bioremediation, both samples without worms recorded higher bioremediation rates.
\end{abstract}

() 2012 International Formulae Group. All rights reserved.

Keywords: Concentration, Time, Total petroleum hydrocarbon, vermicomposting, Eudrilus eugeniae

\section{INTRODUCTION}

Used engine oil (UEO) refers to any lubricating oil that has served its purpose in a vehicle and is withdrawn from the meant area of application (Kojevnikova, 1999). Engine oil is a complex mixture of hydrocarbons and other organic compounds, including some organometallic constituents (Obidike 1985;
Butler and Mason, 1997) used as lubricants to smoothen engine operation (Lee et al., 1992). Used motor oil contains metals and heavy polycyclic aromatic hydrocarbons that could contribute to chronic health hazards including mutagenicity and carcinogenicity (Lee et al., 1992). 
In some developing countries, used engine oil is discharged into the environment. In Nigeria for instance, about 20 million gallons of waste engine oil are generated annually from mechanic workshops and discharged carelessly into the environment (Faboya, 1997; Adegoroye, 1997). According to USEPA (1996), a liter of used engine oil is enough to contaminate one million gallons of freshwater. Used engine oil also renders the environment unsightly and constitutes a potential threat to humans, animals, and vegetation (Adelowo et al., 2006). As the usage of petroleum hydrocarbon products increase, soil contamination with diesel and engine oils is becoming one of the major environmental problems. As a result, environmental pollution with used engine oil continues to generate interest.

Bioremediation is the enhancement of live soil organisms such as fungi, bacteria and plant to break down hydrocarbon and other organic contaminants. Bioremediation involves the transformation of complex or simple chemical compounds into non hazardous forms by biological agents. It is a relatively cheap and effective means of cleaning the environment and involves the application of organisms and nutrients such as inorganic or organic phosphate and nitrogen to the contaminated soil (Atlas and Bartha, 1992). The heavy metal content of soil is an important factor when bioremediation is considered for oil contamination cleanup (Vidali, 2001).

Due to their biological, chemical and physical actions, earthworms can be directly employed within bioremediation strategies to promote biodegradation of organic contaminants. Earthworms have been shown to aerate and bioturbate soils and improve their nutritional status and fertility, which are variables known to limit bioremediation. Earthworms have also been shown to retard the binding of organic contaminants to soils, release previously soil-bound contaminants for subsequent degradation, and promote and disperse organic contaminant degrading microorganisms (Hickman and Reid, 2008). Schaefer and Juliane (2007) studied the bioremediation of crude oil contaminated soil using different earthworm species and concluded that earthworms may trigger the degradation process and might therefore, be applied in the remediation of oil contaminated soil with moderate total petroleum hydrocarbon (TPH) values. Ameh et al. (2011) reported the survival of earthworms in used engine oil (from automobiles) contaminated soil. They reported that used engine oil concentration level tolerable to earthworms was dependent on the source of the used engine oil (the engine type).

The aim of this work was to study the effect of earthworms and organic amendments on the bioremediation of used engine oil contaminated soil.

\section{MATERIALS AND METHODS \\ Study area}

This investigation was carried out at Ahmadu Bello University, Samaru, Zaria. The soil, used engine oil and earthworm samples used were collected from Samaru, Zaria. Adult earthworms Eudrilus eugeniae, ranging in weight from 0.3 to $0.5 \mathrm{mg}$ each, were collected from the soil of the Ahmadu Bello University Campus. Poultry manure was collected from the poultry section of the National Animal Production and Research Institute (NAPRI), Ahmadu Bello University, Zaria. Used engine oil was obtained from Dogo Iche motorcycle mechanic workshop, Zaria. Soil samples were collected from various sites around Samaru where analyzed for soil textural class using the hydrometer method (Bouyoucos, 1962)

\section{Identification and analysis of materials}

Some earthworm samples were sent to the Department of Biological Sciences, Landmark University, Kwara State, Nigeria 
for identification and the remainder used for study within 72 hours after collection. The carbon, phosphorus and nitrogen content of the soil and manure were determined according to the method of AOAC (2005).

\section{Characterization of used engine oil}

The composition of the used engine oil was determined by mixing two drops of it with 5 milliliters of dichloromethane and analyzing the supernatant after settling using GCMS (GCMS-QP2010 Plus Shimadzu, Japan). The initial column oven temperature was kept at $60{ }^{\circ} \mathrm{C}$ for five minutes and then raised by $20{ }^{\circ} \mathrm{C}$ per minute to $140{ }^{\circ} \mathrm{C}$ and then at $5{ }^{\circ} \mathrm{C}$ per minute to $200{ }^{\circ} \mathrm{C}$. It was held at $200{ }^{\circ} \mathrm{C}$ for 5 minutes and then raised by $4{ }^{\circ} \mathrm{C}$ per minute to $280{ }^{\circ} \mathrm{C}$. The total run time was 49 minutes.

\section{Effect of UEO concentration}

1 kilogram of soil contaminated with 5 $\mathrm{g}$ UEO/kg of soil was mixed with $5 \mathrm{~g}$ of poultry manure. 1 gram of the manure was littered on the surface (Schaefer and Juliane, 2007). This was repeated using other concentrations of UEO contaminated soil (10, 15 and $20 \mathrm{~g} \mathrm{UEO} / \mathrm{kg}$ ). 10 earthworms were introduced into each sample: OECD (2010) recommends a minimum amount of $50 \mathrm{~g}$ dry weight of soil per worm. The total petroleum hydrocarbon (TPH) of the soil $(\mathrm{g} / \mathrm{kg})$ was determined every two weeks for a total of 6 weeks. TPH was determined using the toluene cold extraction method as described by Adesodun and Mbagwu (2008). Soil sample $(5 \mathrm{~g})$ was weighed into $50-\mathrm{ml}$ flask and $10 \mathrm{ml}$ of toluene (AnaLar grade) was added. After shaking for 30 minutes on a shaker (Tamson, Holland) and allowing to stand for an hour in an air tight sample bottle, the supernatant was extracted and its absorbance measured at 420 nm using spectrophotometer (CE202 Ultraviolet spectrophotometer). TPH with time was estimated using a calibration curve prepared by recording the absorbance of supernatants obtained by mixing $5 \mathrm{~g}$ of UEO contaminated soil, from known concentration of UEO contaminated soil $(1-20) \mathrm{gUEO} / \mathrm{kg}$ of soil, with $10 \mathrm{ml}$ of toluene.

\section{Effect of worm concentration on} bioremediation and microbial biomass

1 kilogram of soil was spiked with $6 \mathrm{~g}$ of poultry manure, contaminated with $20 \mathrm{~g}$ of UEO and 5 earthworms were introduced. Other samples were also produced but with varying numbers of earthworms introduced $(0$, 10, 15 and 20). After every two weeks, the TPH was determined using the toluene cold extraction method. The microbial count of the samples at the start of the experiment and after every two week was determined using the plate count method (Talaro and Talaro, 2002). The culture media used was nutrient agar. Serially diluted samples $(0.1 \mathrm{ml})$ were plated on nutrient agar medium (Oxoid) supplemented with $50 \mu \mathrm{g} / \mathrm{ml}$ nystatin to suppress the growth of fungi. Triplicate plates were incubated at $30{ }^{\circ} \mathrm{C}$ for $24 \mathrm{~h}$ before the colonies were counted.

\section{Effect of Mixing/Tilling Versus Earthworm Assisted Bioremediation}

This investigation was aimed at comparing the effect of the activities of earthworm with manual tilling/mixing in the process of bioremediation. Four samples were prepared in which 5 grams of UEO was added to 500 grams of soil and thoroughly mixed in plastic test containers. 5 grams of poultry manure was added and again thoroughly mixed manually. Water was added to $60 \%$ water holding capacity and the content of the container was again thoroughly mixed. To one of the test containers was added 15 earthworms and to another 10 earthworms. One of the remaining two was labeled MX (mixed) as the content of the container was regularly stirred mixed while the other was labeled UMX (unmixed) as it was unstirred throughout the test period, save for the initial mixing when the content of the test container 
was thoroughly mixed. The test containers were covered with muslin cloth to allow air while preventing earthworms from escaping. At intervals of two (2) weeks, microcosms were prepared for each sample by mixing 5 grams of soil collected from four different areas for isolation and enumeration of bacteria and determination of total petroleum hydrocarbon. The process lasted 14 weeks and all samples where produced in duplicates. GCMS analysis was conducted was conducted at time $\mathrm{t}=0$ weeks and at $\mathrm{t}=14$ weeks (for mixed sample and sample with 15 worms).

Microbial identification was conducted on soil sample from MX and the sample with 15 worms. Twenty five (25) grams of soil sample was mixed with $225 \mathrm{mls}$ of normal saline $\left(\mathrm{NaCl}+\mathrm{H}_{2} \mathrm{O}\right)(1: 10)$. Ten fold dilution were then prepared, that is $1 \mathrm{ml}$ of the diluted sample (stock) was transferred into $9 \mathrm{ml}$ of sterile normal saline $\left(10^{1}\right)$ by using a sterile pipette, this was repeated to obtain $10^{2}, 10^{3}$, $10^{4}$ and $10^{5}$ dilutions respectively. Using a sterile pipette 0.1 milliliters of $10^{5}$ dilution was aseptically transferred into sterile plate count agar (PCA) plates in duplicates. With the aid of a sterile bend glass rod, the inoculum was spread on the surface of the culture medium (PCA). The inoculated plates were incubated at $37{ }^{\circ} \mathrm{C}$ for 24 hours. The isolates were Gram stained and observed under the microscope to determine the gram reaction, morphology and the presence of spores. The organisms were identified and characterized. Gram-reaction, motility, shape and color of colony, catalase, oxidase activities, were checked.

\section{RESULTS}

\section{Elemental analysis of poultry manure}

The composition of nitrogen, carbon and phosphorus in the poultry manure was found to be $2.89,45.58$ and $1.90 \%$ respectively.

\section{Analysis of used engine oil}

The chromatogram obtained from the GC analysis of the used engine oil is presented in Figure 1. The MS comparison of Table 1 gives the composition of the used engine oil.

Effect of used engine oil concentration on earthworm assisted bioremediation

The effect of variable concentration of UEO in soil is presented in Figure 2.

\section{Effect of worm concentration on bioremediation}

The effect of worm concentration on vermin-assisted bioremediation of used engine oil contaminated soil treated with poultry manure is presented in Figure 3. The result of GCMS analysis of the extract from the soil samples, using dichloromethane, is presented in Table 2. The effect of worm activity on microbial biomass is presented in Figure 4.

The effect of tilling (mixing) and earthworm on bioremediation

Figure 5 presents the result of the comparison between the activity of earthworm and manual mixing of the soil. The effect of manual mixing (tilling) on microbial biomass is presented in Figure 6.

\section{Microbial isolation and identification}

From the tests conducted on the soil samples, the bacteria identified in the earthworm untreated and treated sample are presented in Table 3. The microorganism identified in both samples was the same: Bacillus cereus. 
Table 1: GCMS analysis of motorcycle used engine oil.

\begin{tabular}{ll}
\hline Components & \% Composition \\
\hline C9 - C19 & 15.80 \\
C20 - C29 & 26.42 \\
C30 - C54 & 56.78 \\
\hline
\end{tabular}

Table 2: MS analysis on the effect of earthworm concentration on the composition of UEO in bioremediation.

\begin{tabular}{llll}
\hline \multicolumn{5}{c}{ Composition of UEO } \\
\hline & Day $\mathbf{0}$ & No worm $\mathbf{t}=\mathbf{4 2}$ day & $\mathbf{2 0}$ worms, $\mathbf{t}=\mathbf{4 2}$ days \\
C9 - C19 & 15.8 & 97.29 & 92.08 \\
C20 - C29 & 26.42 & 2.71 & 7.91 \\
C30 and Above & 56.78 & 0 & 0 \\
\hline
\end{tabular}

Table 3: Identification of bacteria in used engine oil contaminated soil, treated with poultry manure after 14 weeks of bioremediation.

\begin{tabular}{llllllllll}
\hline Sample & $\begin{array}{l}\text { Gram } \\
\text { reaction }\end{array}$ & Shape & Indole & MR & VP & Citrate & Catalase & Coagulase & Organism \\
\hline No worm & + & Rod & - & - & - & - & + & - & \\
30 worms/ & + & Rod & - & - & - & - & + & - & $\begin{array}{l}\text { Bacillus } \\
\text { cereus }\end{array}$ \\
kg soil & & & & & & & & & \\
\hline
\end{tabular}

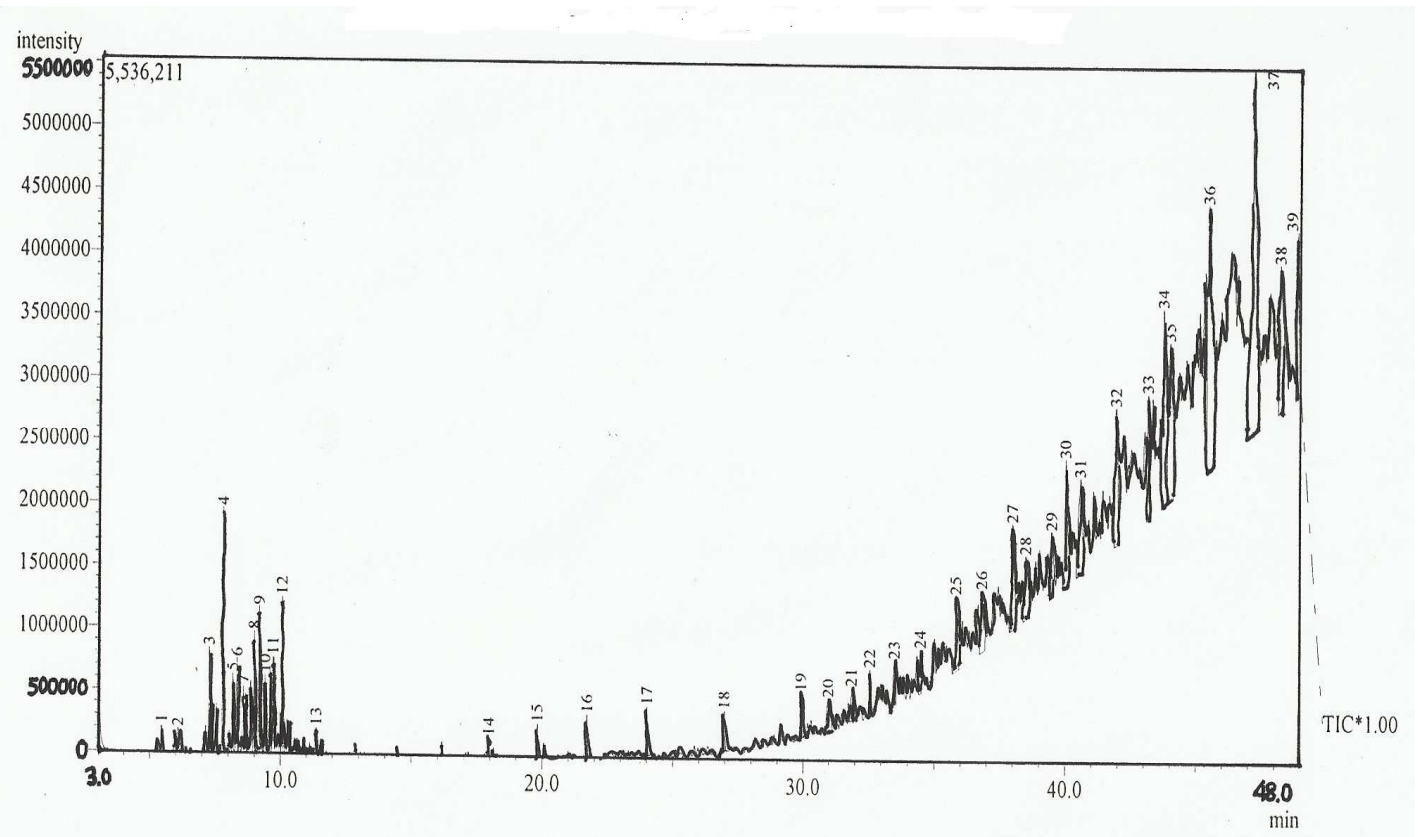

Figure 1: GC analysis of motorcycle used engine oil. 


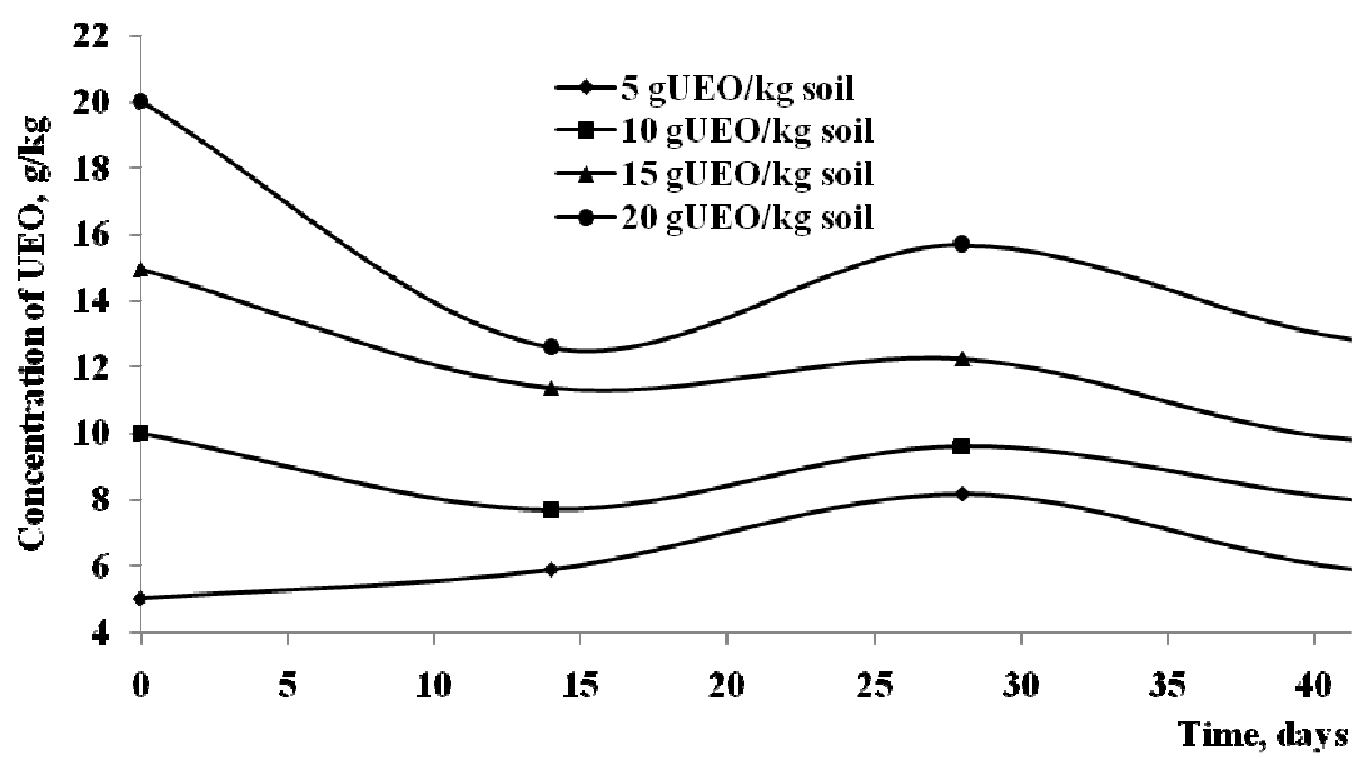

Figure 2: Effect of initial used engine concentration on bioremediation by vermicomposting.

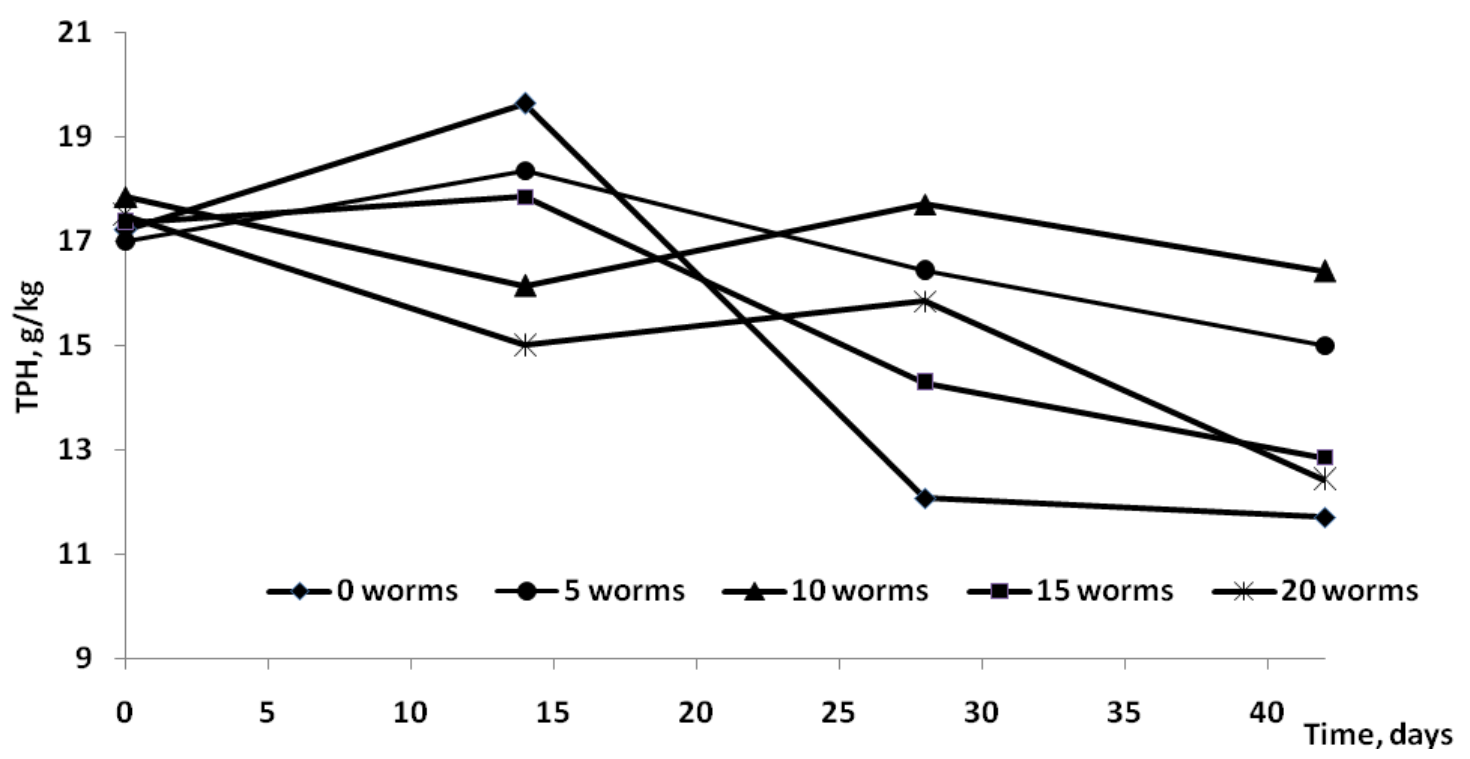

Figure 3: Effect of earthworm concentration on bioremediation by vermicomposting. 


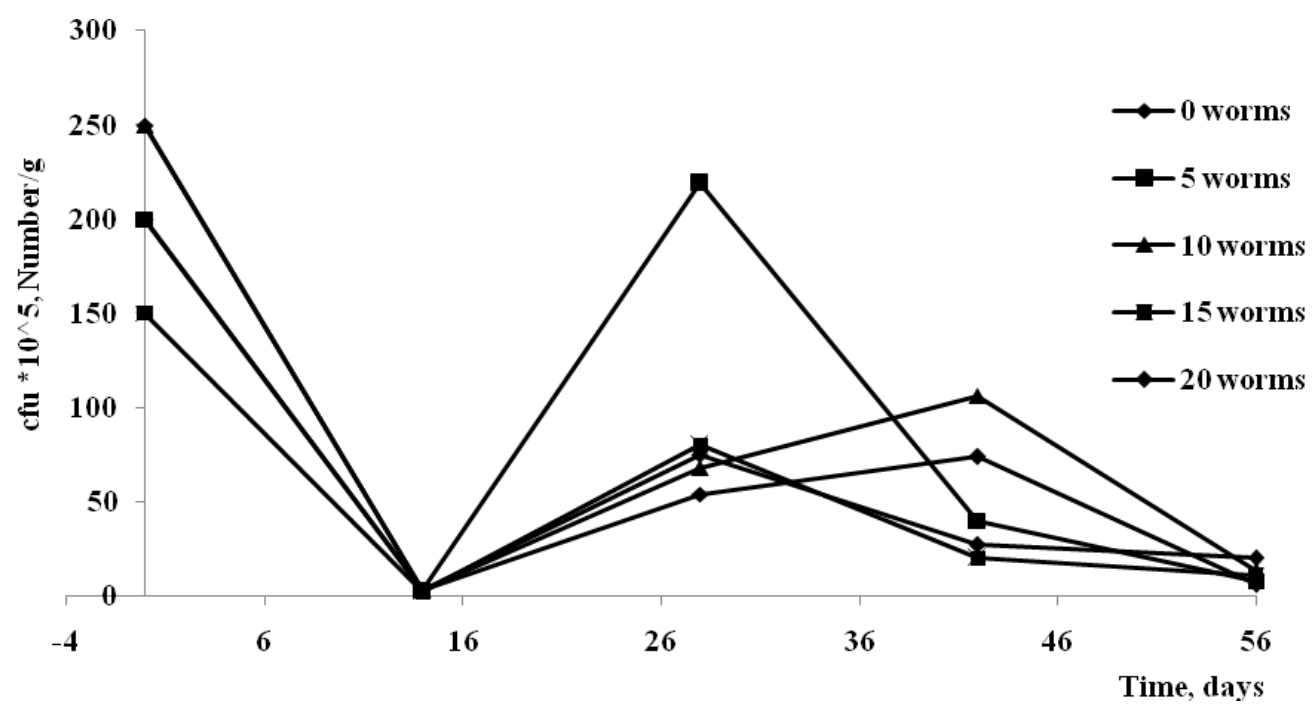

Figure 4: Effect of Vermicompostiong on Microbial Biomass.

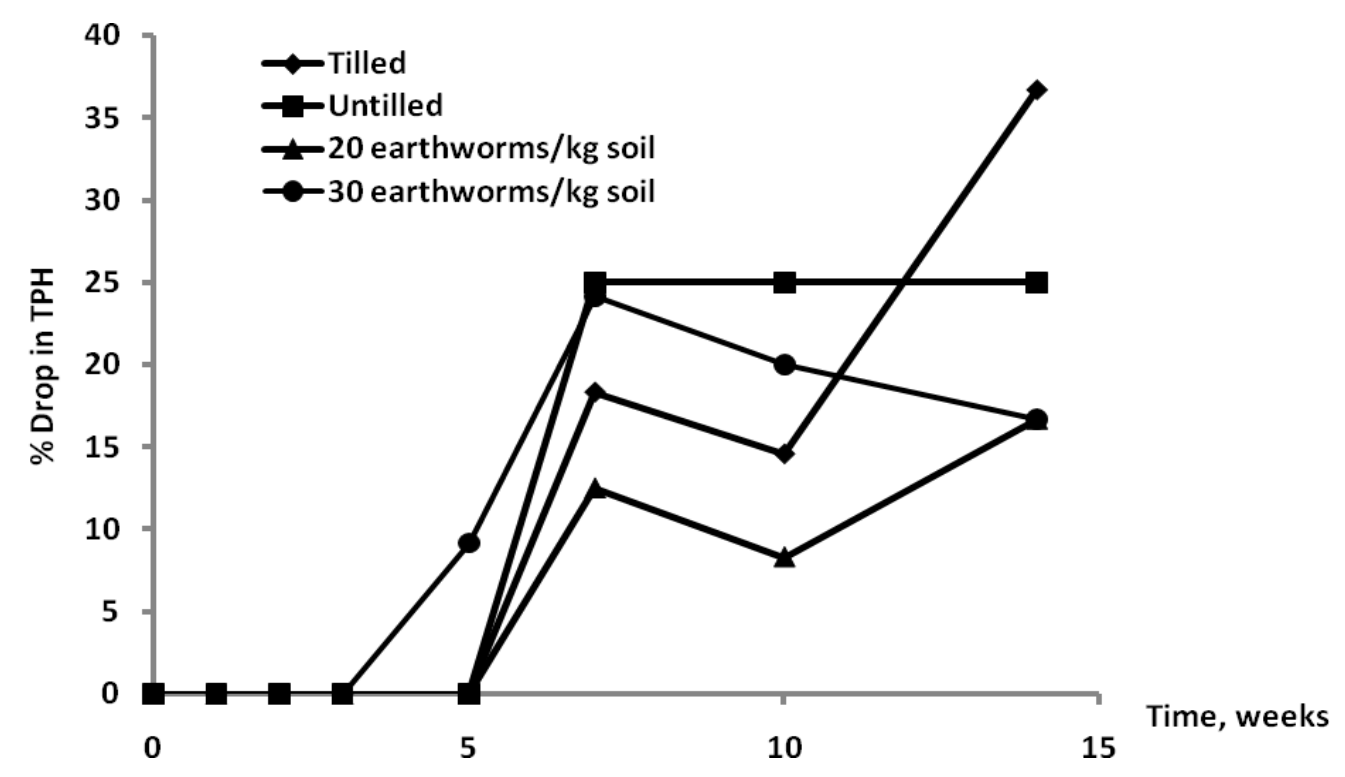

Figure 5: Effect of tilling/earthworm on bioremediation. 


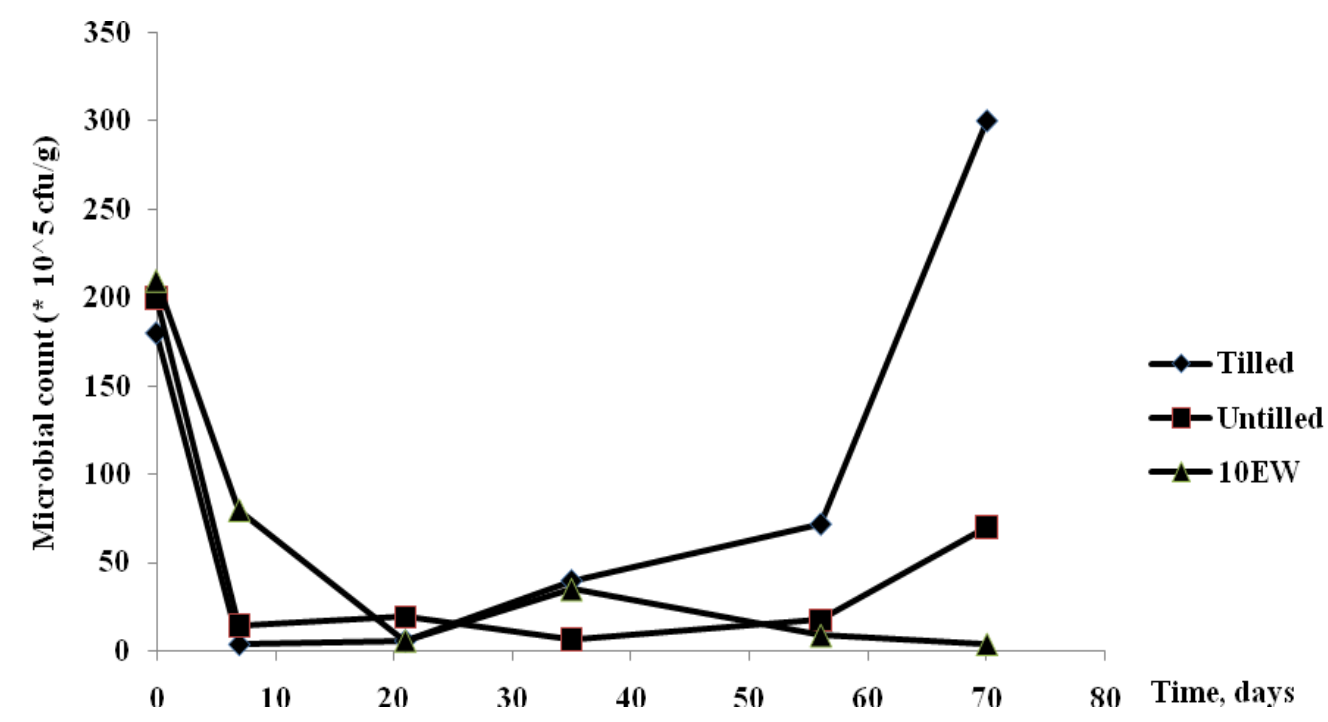

Figure 6: The effect of tilling on microbial biomass.

\section{DISCUSSION}

\section{Analysis of used engine oil}

The GCMS analysis of the used engine oil presented in Table 1 indicated that the oil contained carbon up to $\mathrm{C}_{54}$. According to Hunt (1996) lubricating oil normally ranges from about carbon $\left(\mathrm{C}_{20}\right)$ to $\mathrm{C}_{35}$, but can be as low as $\mathrm{C}_{15}$ and as high as $\mathrm{C}_{50}$, depending on the distillation process. The alteration in the composition of the used oil may be as a result of decomposition and the possibility of gasoline introduction while in use.

Effect of used engine concentration on earthworm assisted bioremediation

As shown in Figure 2, it was in the soil with the highest initial concentration of UEO that the degradation was highest. A similar report was made by Schaefer (2001). This may be a result of an enhancement in microbial activity as more carbon (in the form of used engine oil) is available as energy source. For initial used engine concentration of $5,10,15$ and $20 \mathrm{~g} / \mathrm{kg}$ soil, the drop in total petroleum hydrocarbon was found to be -
$16.91,20.82,34.68$ and $36.28 \%$ respectively after 42 days of treatment. This may suggest that earthworm assisted bioremediation of used engine oil contaminated soil is favored by increase in initial used engine oil concentration. This may however not be true for used engine oil from motorcar which was reported by Ameh et al. (2011) to be increasingly lethal to earthworm with increasing contamination level. The negative value recorded for the $5 \mathrm{~g} / \mathrm{kg}$ used engine oil contaminated denoting an apparent increase in oil content could have been a result of two probable factors (1) the extraction of biogenic organic compounds from the vegetal organic matter (primarily from the organic amendment used) by toluene which can affect the TPH value. (2) the initial formation of organic molecules of higher molecular weights on combination with oxygen in the process of bioremediation. Further investigation can reveal the cause of this seeming anomaly. Either way, the total concentration of organic compounds (soluble in toluene) in the soil increased. 
Effect of worm concentration on bioremediation

As shown in Figure 3, there was an initial increase in TPH for most of the samples probably as a result of the extraction of biogenic organic compounds from the vegetal organic matter (Chaîneau et al., 1997). Samples with 0, 15 and 20 worms showed the highest drop in TPH with time. The samples with 5 and 10 earthworms had the least drop in TPH over the 42 day period considered. The percentage drop in TPH for the samples with $0,5,10,15$ and 20 earthworms on day 42 was $31.95,11.75,8,25.93$ and $28.98 \%$ respectively. Under the condition of the study the earthworms will eventually starve to death as the nutrient (manure) is not replenished. This implies that without addition of nutrients (in this case manure) the earthworms will eventually begin to starve to death starting with the samples with the highest concentration of worms.

Generally the sample without worms performed better than all the samples with worms. It can be seen that with regards to TPH drop alone (and within the range of earthworm concentration considered), there is no significant advantage in introducing earthworms for bioremediation of used engine oil contaminated soil. It has been reported that although the action of earthworm generally increase the mineralization of soil carbon, earthworms can also decrease mineralization of carbon by contributing to the formation of stable soil aggregates in which carbon is protected from further breakdown. There is also the possibility that the microbial community has been affected by the joint action of the petroleum hydrocarbon carbon contamination and the presence of the worms to give this result. Theoretical also, it may be possible to reach a concentration in which the bioremediation kinetics of the earthworm treated sample will surpass that of the without earthworm system. The result of this investigation differs widely from the finding of Schaefer and Juliane, 2007: TPH concentration decreased by $30-42 \%$ in samples with Eudrilus eugeniae, after 28 days of incubation also the TPH concentration of the samples without earthworms was not significantly decreased after 28 days (9-17\%) when earthworm was used in the bioremediation of crude oil contaminated soil. They also concluded that addition of earthworms improved bioremediation rate more than manual tilling (in the absence of earthworms). Generally, increase in earthworm concentration resulted in an increased rate of bioremediation. When the bioremediation data was fitted to the $1^{\text {st }}$ order bioremediation kinetics the fit was found to be poor $\left(\mathrm{R}^{2}<0.5\right)$.

The GCMS analysis of Table showed that for the sample without worms and that with 20 worms, on day 42 , the $\mathrm{C}_{30}$ and above fraction of the remaining oil had been eliminated. Such an observation was reported by Prince et al. (2007), who stated that within a complex mixed gasoline mixture; larger nalkanes were more readily degraded than the smaller n-alkanes. They sample with 20 worms however more C20 - C29 than the sample without worms had.

\section{The effect of tilling (mixing) and earthworm on bioremediation}

As shown in Figure 5, drop in TPH for most of the samples began after the fifth week. At $\mathrm{t}=7$ weeks the samples with 15 earthworms (15EW) had the highest drop in TPH which was comparable to the untilled sample $(24.16 \%$ and $25 \%$ respectively). Thereafter its TPH increased probably as a result of starvation and death of the worms. The tilled (mixed) sample and the sample with 10 earthworms (10EW) indicated a slower initial drop in TPH but the mixed sample picked up after the $\mathrm{t}=10$ weeks to give the highest drop in TPH at $\mathrm{t}=14$ weeks of $36.67 \%$. This result showed for the initial used engine oil concentration considered after 14 weeks of treatment the both samples without worms recorded higher drops in TPH compared to the sample with worms. The result also showed that the drop in TPH is a 
function of earthworm concentration with higher concentrations favoring higher rates. Finally that when earthworms are considered for use in bioremediation it is important to reintroduce nutrient (poultry manure in this case) to sustain the worms (since they cannot feed on used engine oil) and to maintain the pace of the bioremediation process.

The effect of the presence of earthworm on the microbial community is as shown in Figures 4 and 6. The microbial count was found to decrease and increase indiscriminately. According to Granatstein and Bezdicek (2003) there needs to be at least a 10-fold difference in microbial number to be meaningful because of variability in measuring organisms. Figures 4 and 6 therefore shows that presence of earthworms had no significant effect on microbial count that all samples (untreated/earthworm treated) had similar number of bacteria at the various times and would perform the same if all else was equal.

\section{Microbial Identification}

Table 3 presents the result of the biochemical test on the isolates from sample MX and the earthworm inoculated sample (30 earthworms $/ \mathrm{kg}$ soil). Bacillus cereus was the most prevalent microbe being found in both samples. Bacillus is ubiquitous in nature and has been postulated to be more tolerant to high levels of hydrocarbons in soil due to their resistant endospores. Bacillus Cereus is an organism occurring naturally in most foods and it can cause two different forms of food poisoning, diarrhoeal and emetic, both caused by toxins produced by the bacteria. Kebria et al. (2009) reported that a strain of bacillus native to Tehran Bacillus cereus, showed great potential for in-situ remediation of diesel-contaminated soil in oil refinery sites.

\section{Conclusion}

1. The use of earthworm did not show an advantage in terms of TPH removal when compared to samples without worms.
2. Earthworm (Eudrilus eugeniae) was found to affect the bioremediation of used engine oil contaminated soil, increase in earthworm concentration increasing the rate of bioremediation.

3. The bioremediation process could not be described by any simplified bioremediation kinetics. The $\mathrm{R}^{2}$ values for the linearized first and second other bioremediation rate laws were found to be $<0.5$.

4. Manual mixing of the soil was shown to have the highest effect on TPH reduction when compared to an unmixed sample (without worms) and samples with earthworms, after a 14 week period.

\section{ACKNOWLEDGEMENTS}

Authors thank the Science and Technology Education Post-Basic (STEP-B) Innovators of Tomorrow (IOT) and the University Board of Research (Ahmadu Bello University, Zaria) for their financial support.

\section{REFERENCES}

Adegoroye G. 1997. Environmental considerations in property design, urban development and renewal. In Dimensions of Environmental Problems in Nigeria, Akinjide $\mathrm{O}$ (Ed). Friedrich Ebert Foundation; 12-25.

Adelowo OO, Alagbe SO, Ayandele AA. 2006. Time-dependent stability of used engine oil degradation by cultures of Pseudomonas fragi and Achromobacter aerogens. African Journal of Biotechnology, 5(24), 2476- 2479.

Adesodun JK, Mbagwu JSC. 2008. Biodegradation of waste lubricating petroleum oil in a tropical alfisol as mediated by animal droppings. Bioresource Technology, 99: 5659-5665.

Ameh AO, Mohammed-Dabo IA, Ibrahim S, Ameh JB, Azienge CD, Tanimu Y. 2011. Earthworm survival in used engine oil contaminated soil spiked with manure. Int. J. Biol. Chem. Sci., 5(3): 923-929. 
AOAC (Association of Official Analytical Chemists). 2005. Methods of Analysis. AOAC: Washington D. C.

Atlas RM, Bartha RC 1992. Hydrocarbon biodegradation and soil spill. In Bioremediation of Engine oil-Polluted Soil by Pleurotus tuber-regium Singer, a Nigerian White-rot Fungus, Adenipekun CO (Ed). African Journal of Biotechnology, 7(1): 055-058.

Bouyoucos GJ. 1962. Hydrometer method improved for making particle size analysis of soils. Agron. J., 54: 464-465.

Butler CS, Mason JR. 1997. Structurefunction analysis of the bacterial aromatic ring-hydroxylating dioxygenases. In Advanced Microbial Physiology (vol. 38). Academic Press Limited; 47-84.

Chaîneau CH, Morel JL, Oudot J. 1997. Phytotoxicity and plant uptake of fuel oil hydrocarbons. J. Environ. Qual., 26: 1478-1483.

Faboya OOP. 1997. Industrial Pollution and Waste Management. In Dimensions of Environmental Problems in Nigeria, Akinjide $\mathrm{O}$ (Ed). Friedrich Ebert Foundation; 12-25.

Granatstein D, Bezdicek D. 2003. Monitoring Soil Microbes, Invisible Helpers, Tilth Producers Quarterly.

Hickman ZA, Reid BJ. 2008. Earthworm assisted bioremediation of organic contaminants. Environment International, 34: 1072-1081.

Hunt JM. 1996. Petroleum Geochemistry and Geology (2nd edn). WH Freeman and Company: New York.

Kebria YD, Khodadadi A, Ganjidoust H, Badkoubi A, Amoozegar MA. 2009. Isolation and characterization of a novel native Bacillus strain capable of degrading diesel fuel. International
Journal of Environmental Science and Technology, 6(3):435-442.

Kojevnikova YV. 1999. Rational ways of preparation of dispersed oil system, $\mathrm{PhD}$ Thesis (unpublished), Russian Oil and Gas University, Moscow, p.133.

Lee LS, Hagwall M, Delfino JJ, Rao PSC. 1992. Partitioning of polycyclic aromatic hydrocarbons from diesel fuel into water. Environmental Science and Technology, 26: 2104-2110.

Obidike DI. 1985. Oil spill contingency planning proc. Inter. Seminar petroleum industry and the Nigerian Environment. $145-156$.

Organisation for Economic Co-operation and Development (OECD). 2010. Guidelines for the Testing of Chemicals: Bioaccumulation in Terrestrial Oligochaetes, 317.

Prince RC, Parkerton TF, Lee C. 2007. The primary aerobic biodegradation of gasoline hydrocarbons. Environ. Sci. Technol., 41: 3316-21.

Schaefer M, Juliane F. 2007. The influence of earthworms and organic additives on the biodegradation of oil contaminated soil. Applied Soil Ecology, 36: 53 - 62.

Schaefer M. 2001. Earthworms in crude oil contaminated soils. Toxicity tests and effects on crude oil degradation. AEHS Contaminated Soil Sediment and Water; 35-37.

Talaro KP, Talaro A. 2002. Foundations in Microbiology $\left(4^{\text {th }}\right.$ edn). McGraw-Hill: Boston; 207- 212.

United States Environmental Protection Agency (USEPA). 1996. Recycling used oil: What can you do? Cooperation Extension Services, ENRI, 317:1-2.

Vidali M. 2001. Bioremediation. An overview. Pure Appl. Chem., 73(7): 1163-1172. 